\title{
Analisa Variasi Foot Valve Dan Jatuh Air Terhadap Karakteristik Pada Pompa Sentrifugal
}

\author{
Fajar Maulana ${ }^{1)}$, Wayan Sujana ${ }^{2)}$ \\ Institut Teknologi nasional Malang \\ Fakultas Teknologi Industri \\ Jalan Karanglo Km.2, Malang \\ Email:fm763572@gmail.com
}

\begin{abstract}
AbSTRAK
Pompa sentrifugal adalah pompa yang mengubah energi kinetik putaran poros dan impeller menjadi tekanan fluida, dimana arah fluida tegak lurus dengan sumbu impeller. Kecepatan fluida dikonversikan menjadi tekanan oleh casing sehingga fluida dapat keluar melalui outlet. Pada kesempatan ini saya mencoba memaparkan hasil penelitian saya tenang analisa variasi foot valve dan jatuh air terhadap karaktristik pada pompa sentrifugal dengan variasi foot valve ukuran $1 / 2,3 / 4$, dan 1 inch dengan variasi ketinggian 1,2, dan 3 meter dengan variasi waktu 1, 2, 3, 4, dan 5 menit. Tujuan penelitian ini untuk mengetahui data mana yang bisa meningkatkan performence pada pompa sentrifugal sebagaimana yang dihasilkan untuk kerja pompa agar kedepannya bisa digunakan pada kehidupan sehari-hari. Dari hasil penelitian saya didapatkan data yang paling efisien adalah data pompa air pada variasi foot valve ukuran 1 inch, dimana data ini memperoleh air cukup banyak khususnya pada ketinggian 1 meter yaitu mendapatkan debit air 30,65 liter/menit atau 510,833 mililiter/detik.
\end{abstract}

Kata Kunci Pompa Sentrifugal, Foot Valve, Ketinggian, Waktu

Paper type Research paper

\section{PENDAHULUAN}

Pompa merupakan salah satu komponen yang paling penting dalam hal pendistribusian cairan (terutama air). Dalam memompa cairan, pompa sentrifugal memiliki peranan yang amat penting, karena paling banyak penggunanya. Karena banyaknya penggunaan tersebut, maka dibutuhkan pompa sentrifugal yang kerjanya maksimum. Penggunaan pompa yang demikian luas dengan berbagai macam jenis dan bentuknya, memerlukan pengetahuan yang cukup untuk merancang, membuat, maupun memilih tipe pompa yang tepat sesuai dengan kondisi dan lingkungan operasi yang dilayaninya. Mulai dari tujuan penggunaannya, jenis dan sifat fluida yang dipompa, keadaan lingkungan, ketinggian, dan kapasitasnya, pemilihan penggeraknya, bahkan sampai instalasi dan perawatannya. Komponen-komponen utama pompa sentrifugal terdiri dari mechanical seal, packing, shaft (poros), shaft-sleeve, vane, kasing pompa, eye of impeller, impeller, wearing ring, bearing, dan discharge. Dimana kerja pompa merupakan salah satu yang menjadi efek langsung dari keadaan aliran cairan (air) masuk dan keluar nozle.

Dalam pendistribusian air (cairan) penggunanan pompa sangat diperlukan untuk memenuhi kinerja dari pompa tersebut,Pompa yang sering digunakan dalam pendistribusian air (cairan) adalah pompa sentrifugal. Masalah yang sering dihadapi dari pompa sentrifugal ini adalah perawatan pompa tersebut Sehingga mengakibatkan kecepatan, daya, dan peforma kerja yang kurang efesien. Dengan merubah variasi head pompa yang berbeda maka akan menghasilkan kecepatan, daya, dan aliran akan maksimal.

Pada penelitian ini penulis mencoba menganalisa variasi foot valve dan jatuh air yang berbeda terhadap karakteristik pada pompa sentrifugal. Variasi ini diharapkan dapat mengetahui data mana yang bisa meningkatkan performence pada pompa sentrifugal sebagaimana yang dihasilkan untuk kerja pompa agar kedepannya bisa digunakan pada kehidupan sehari-hari.

\section{LANDASAN TEORI}

Pompa adalah sebuah alat yang digunakan untuk menggerakan fluida dengan memberikan gaya tekan terhadap fluida yang akan dipindahkan. Dengan meggunakan pompa, fluida dapat dipindahkan baik secara vertikal maupun horizontal. Fluida adalah zat yang partikel - partikelnya bergerak bebas sehingga bentuknya dapat berubah dengan mudah. Secara umum, fluida terbagi menjadi fluida mampu mampat (Compresible) dan fluida tak mampu mampat (Incompresible).

\section{PROSEDUR}

Prosedur penelitian yang dilakukan adalah sebagai berikut :

1. Menyiapkan alat dan bahan yang akan digunakan pada proses penelitian.

2. Meletakkan tandon penampung air pada bagian bawah.

3. Meletakkan pompa air dan tandon penampung air atas pada ketinggian 1 meter, 2 meter dan 3 meter secara 
bergantian.

4. Dan melakukan pergantian variasi foot valve yang berbeda dari $1 / 2,3 / 4$, dan 1 inch.

5. Pada sisi hisap pompa air dipasang sambungan pipa drat luar, pipa sejajar horisontal, stop kran untuk mengisi pancingan air, lalu dipasang juga pipa lurus kebawah dan pada ujung pipa dipasang variasi foot valve.

6. Pada sisi buang pompa air dipasangsambungan pipa drat luar, pipa lurus, sambungan, flow meter, pipa lurus dan pipaelbow mengarah kebawah.

7. Pada bagian bawah pipa elbow diberitandon penampung air atas, agar air yang telah didistribusikan oleh pompa bisa tertampung pada tandon, agar tidak terjadi tumpah.

8. Melakukan analisa data dengan menggunakan flow meter, stopwatch,alat perekam vidio dan saklar ON/OFF pompa air. Yaitu dengan menetralkan angaka terlebih dahulu pada flow meter.

9. Kemudian meletakkan stopwatch disamping flow meter dan setelah semuanya dirasa sudah siap maka menyalahkan rekaman vidio.kemudian stopwatch dan saklar yang ada pada pompa akan dinyalahkan secara bersamaan.

10. Lalu bisa mengambil data berapa liter air yang masuk permenit dan mengambil data pada menit ke 1,2,3,4,5 bisa mendapatkan air berapa liter.

11. Setelah semua data diperoleh pada ketinggian 1 meter, 2 meter, dan 3 meter maka diganti dengan variasi foot valve dari

12. $1 / 2,3 / 4$, dan 1 inch.

13. Dilakukan perbandingan data dan mengambil kesimpulan.

\section{METODOLOGI PENELITIAN}

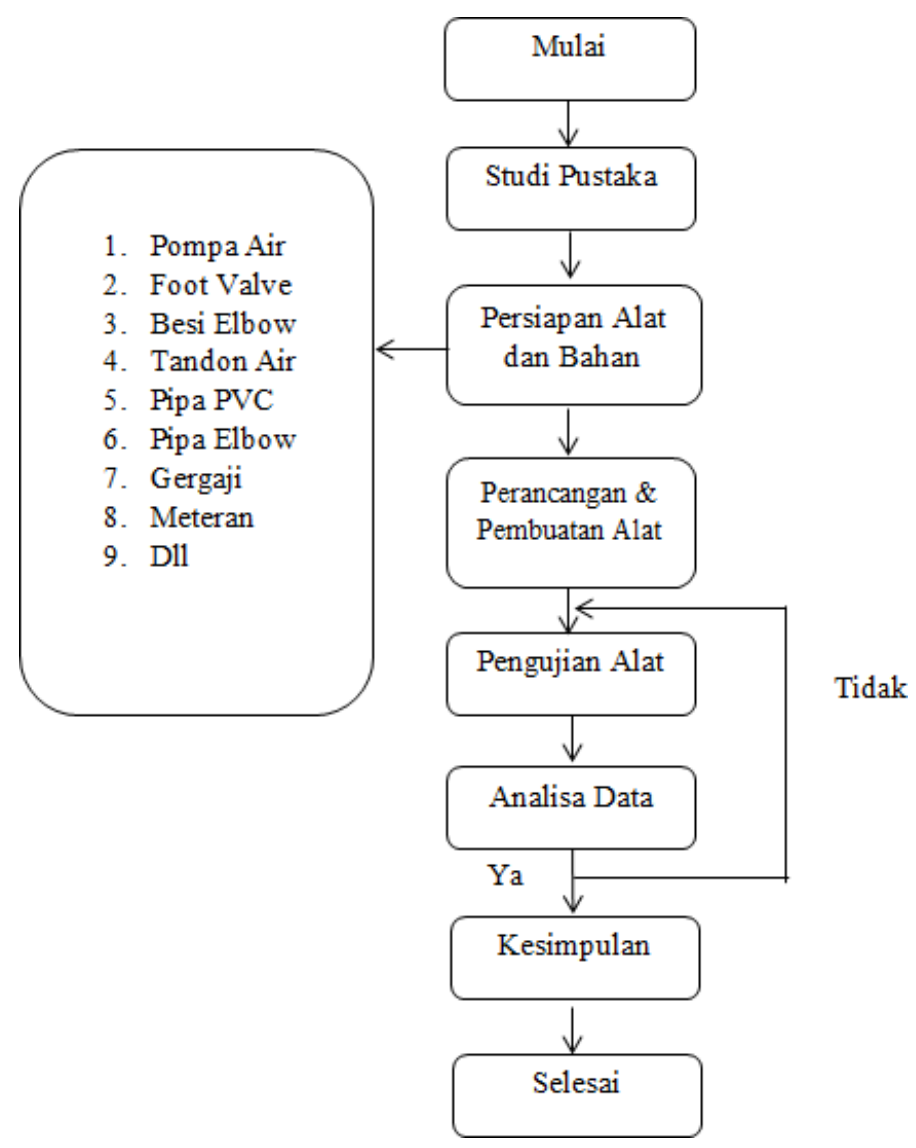

\section{HASIL DAN ANALISA}

Variasi yang digunakan pada penelitian ini adalah :

- Foot Valve : $1 / 2$ inch, $3 / 4$ inch dan 1 inch

- Ketinggian : 1,2 , dan 3 meter

- Waktu : 1, 2, 3, 4, dan 5 menit 
TABLE I. POMPA SENTRIFUGAL UKURAN FoOT VALVE 1/2INCH

\begin{tabular}{|c|c|c|c|c|}
\hline No. & $\begin{array}{c}\text { Dimensi } \\
\text { Valve } \\
\text { D (inch) }\end{array}$ & $\begin{array}{l}\text { Tinggi } \\
\text { Hisap } \\
\text { H (m) }\end{array}$ & $\begin{array}{c}\text { Debit } \\
\mathrm{Q}(/ / \mathrm{min})\end{array}$ & $\begin{array}{c}\text { Debit } \\
\mathrm{Q}(\mathrm{ml} / \mathrm{sec})\end{array}$ \\
\hline 1. & \multirow{3}{*}{$1 / 2$} & 1 & 23,81 & 396,833 \\
\hline 2. & & 2 & 21,26 & 354,333 \\
\hline 3. & & 3 & 19,10 & 318,333 \\
\hline
\end{tabular}

TABLE II. POMPa SENTRIFUGAL UKURAN FoOt VALVE 3/4/NCH

\begin{tabular}{ccccc}
\hline No. & $\begin{array}{c}\text { Dimensi } \\
\text { Valve } \\
\text { D (inch) }\end{array}$ & $\begin{array}{c}\text { Tinggi } \\
\text { Hisap } \\
\mathrm{H}(\mathrm{m})\end{array}$ & $\begin{array}{c}\text { Debit } \\
\mathrm{Q}(/ / \mathrm{min})\end{array}$ & $\begin{array}{c}\text { Debit } \\
\mathrm{Q}(\mathrm{ml} / \mathrm{sec})\end{array}$ \\
\cline { 1 - 3 } 1. & \multirow{2}{*}{$3 / 4$} & 1 & 20,60 & 343,333 \\
\cline { 1 - 3 } & & 2 & 19,98 & 333 \\
\cline { 1 - 1 } 3. & & 3 & 17,14 & 285,666 \\
\hline
\end{tabular}

TABLE III. POMPA SENTRIFUGAl UKURAN FoOT VALVE 1 INCH

\begin{tabular}{ccccc}
\hline No. & $\begin{array}{c}\text { Dimensi } \\
\text { Valve } \\
\text { D (inch) }\end{array}$ & $\begin{array}{c}\text { Tinggi } \\
\text { Hisap }\end{array}$ & $\begin{array}{c}\text { Debit } \\
\mathrm{Q}(\mathrm{m})\end{array}$ & $\begin{array}{c}\text { Debit } \\
\mathrm{Q}(\mathrm{ml} / \mathrm{min})\end{array}$ \\
\cline { 1 - 3 } 1. & & 1 & 30,65 & 510,833 \\
\cline { 1 - 3 } 2. & 1 & 2 & 30,07 & 501,166 \\
\cline { 1 - 1 } 3. & & 3 & 25,42 & 440,333 \\
\hline
\end{tabular}

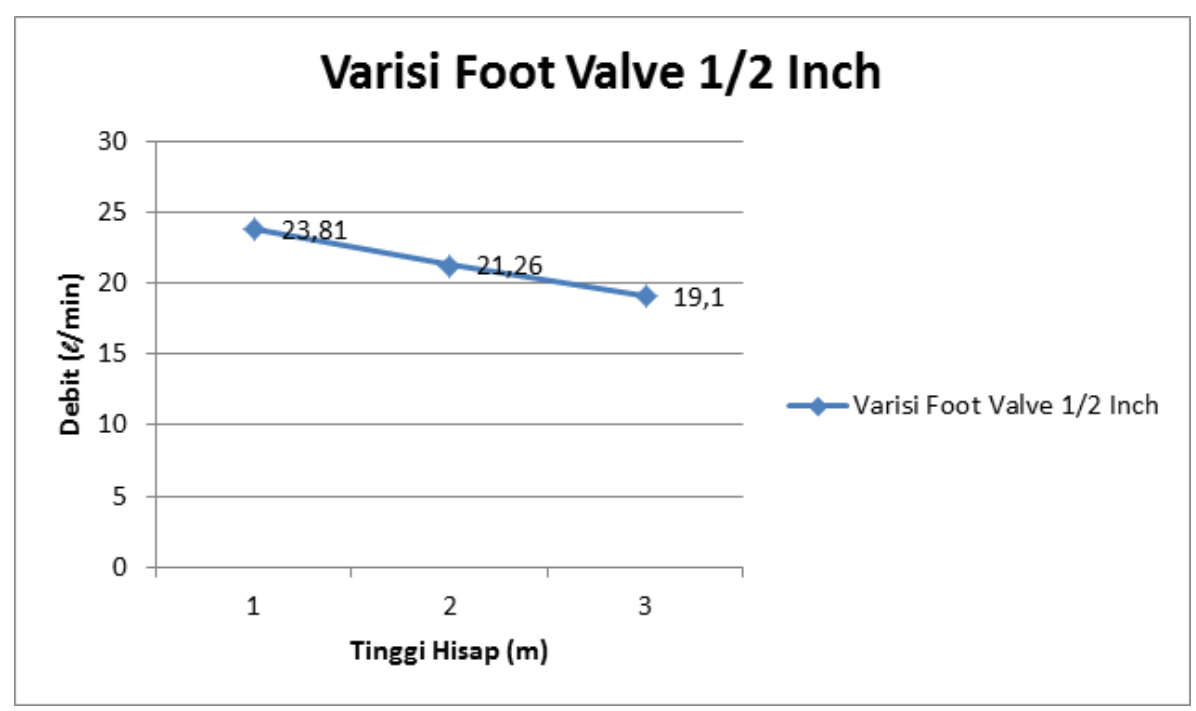

Fig. 1. Grafik perbandingan variasi foot valve 1/2inch terhadap debit air dan ketinggian

Berdasarkan grafik diatas pada variasi foot valve $1 / 2$ inch terhadap debit air dan ketinggian dapat diketahui bahwa pada ketinggian 1 meter didapatkan rata rata air 23,81 liter/menit, pada ketinggian 2 meter didapatkan rata rata air 21,26 liter/menit, dan pada ketinggian 3 meter didapatkanrata rata air 19,10 liter/menit. 


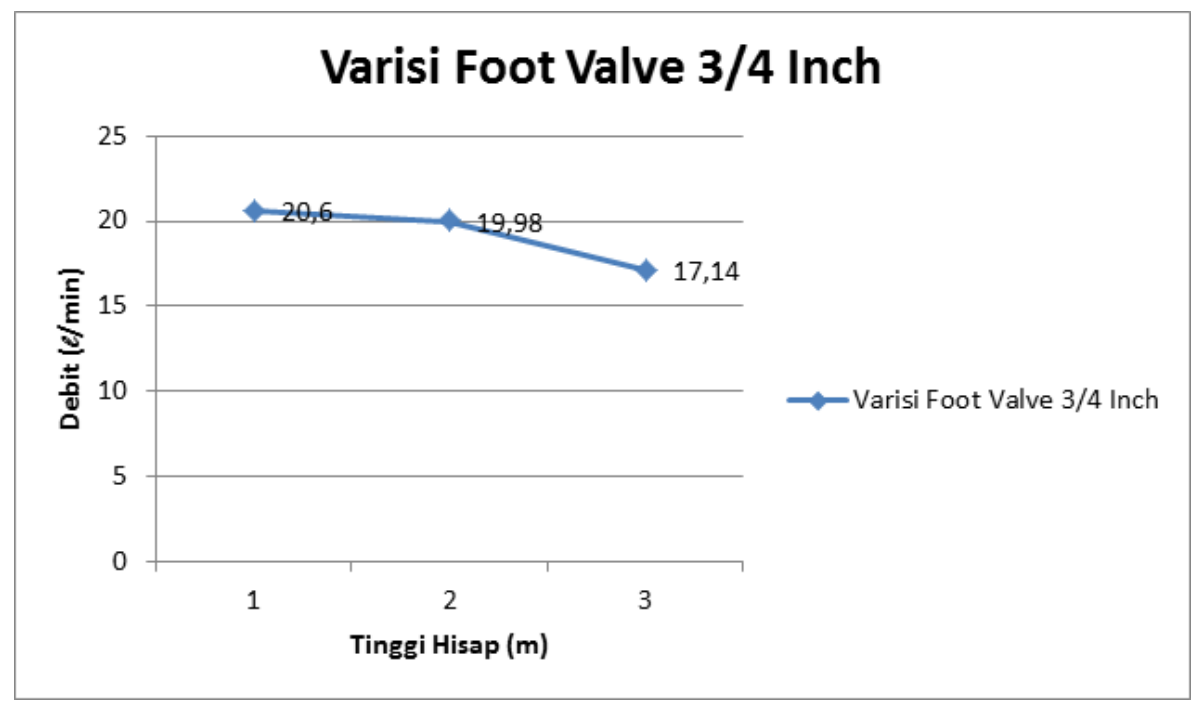

Fig. 2. Grafik perbandingan variasi foot valve 3/4inch terhadap debit air dan ketinggian

\section{KESIMPULAN}

1. Dari hasil pengujian dengan 3 variasi foot valve, 3 variasi ketinggian, dapat disimpulkan bahwa data yang paling efisiensi lebih baik adalah pada variasi foot valve ukuran 1 inch yang mendapatkan debit rata rata air 30,65 liter/menit

2. Dari hasil pengujian ini juga dapat disimpulkan data paling rendah adalah pada variasi foot valve ukuran $3 / 4$ inch dengan mendapatkan debit rata rata air 17,14 liter/menit

3. Dapat disimpulkan juga jika air pada bak/tandon hisap yang ada dibagian bawah masih penuh, maka tekanan air masih besar,sehingga air yang dipompakan juga mengalir cukup deras.

4. Dapat disimpulkan bahwa semakin tinggi letak pompa air, maka semakin berat untuk menghisap cairan fluida dan semakin rendah letak pompa air, maka semakin kencang untuk menghisap cairan fluida.

5. Dapat disimpulkan juga, jika semakin besar variasi foot valve-nya, maka semakin kencang pompa air untuk menghisap cairan fluida.

\section{DAFTAR PUSTAKA}

1. Bendris, Hutabarat, 2019. Analisis unjuk pompa sentrifugal dengan variasi head. Skripsi. Jurusan teknik mesin. Fakultas teknik. Universitas medan area: Medan.

2. Fransiskus, Kale, Wutun, Wadan, 2011. Pompa sentrifugal kecepatan rendah jumlah sudu 3 dengan head 2,1 meter. Skripsi. Program Studi Teknik Mesin. Fakultas sains dan teknologi. Universitas sanata dharma: yogyakarta.

3. Harianto, Bagus. Enterprise UniversityPerbaikan Centrifugal Pump (Single Stages).

4. Muhammad Iqbal Fakhrudin, 2018. Perancangan pompa sentrifugal untik water treatment plant kapasitas $0.25 \mathrm{~m} 3 / \mathrm{s}$ padakawasan industri karawang, Jurusan Teknik Mesin, Fakultas Teknik, Universitas Pancasila: Jakarta.

5. Pompa. keluargasepuh86.blogspot.com/2017/08/je nis-jenis-pompa.html.

6. Thoharudin, Arif Setyo Nugroho, Stefanus Unjanto, 2014. Optimasi tinggi tekan dan efisiensi pompa sentrifugal dengan perubahan jumlah sudu impeler dan sudut sudu keluar impeler menggunakan simulasi computational fluid dynnamics.Jurnal teknik mesin. 